\title{
First steps to creating high impact theory in marketing
}

\author{
Ruth N. Bolton ${ }^{1}$ \\ Accepted: 12 October 2020 / Published online: 28 November 2020 \\ (C) Academy of Marketing Science 2020
}

\begin{abstract}
The business research ecosystem can be transformed by responsible research principles. This commentary offers concrete guidance for developing high impact theory; it provides a tool to assess research benefits and identify participating stakeholders. It also calls for improving doctoral training, countering risk aversion in research topic selection, re-aligning faculty incentives, and leveraging academic institutions.
\end{abstract}

Keywords Responsible research $\cdot$ Marketing theory $\cdot$ Stakeholders $\cdot$ Impact $\cdot$ Ecosystem $\cdot$ Research priorities

Research is formalized curiosity. It is poking and prying with a purpose.

-Zora Neale Hurston (1942), p. 91

I have been asked to offer some reflections on the essays by Key et al. (2020), hereafter called KCFSP. Their work is thought-provoking and a call to action. This commentary begins by discussing my views on four key issues raised by KCFSP-including points of both agreement and disagreement. These four issues are: the purpose of conceptual research in marketing, changes in the marketing discipline, pathways for creating impact, and the relationship between research topics and impact. Then, the commentary offers my vision of a way forward to create impactful research. It identifies practical steps for researchers who seek to generate high impact conceptual work and create an ecosystem that values high impact work.

\section{The purpose of research in marketing}

Many marketing thought leaders believe that theory can contribute to knowledge development about marketing

Ruth N. Bolton

Ruth.Bolton@asu.edu

1 W. P. Carey School of Business, Arizona State University, P. O. Box 874106, Tempe, AZ 85287-4106, USA phenomena that (ultimately) has impact-thereby creating a better world (e.g., Brown et al. 2005). Yet, KCFSP characterize most marketing scholars as focused on demand generation (or, arguably stimulation) and fulfillment with limited interest in the marketing system. This characterization reflects a diminished view of the real scope and importance of marketing as it is understood by many marketing thought leaders (e.g., Tsui 2016; Wilkie 2005; Wilkie and Moore 1999, 2003). In the view of many marketing scholars (including me), our field has a greater purpose: to develop knowledge about the aggregate marketing system-that (in particular) improves individual, organizational, societal and environmental well-being.

\section{Change in the dominant logic of marketing}

The marketing discipline is always changing (Bolton 2017, 2020)-but is it changing for the better or worse? In his excellent historical review, Ferrell describes how supply chain management originated within marketing but (today) is considered a distinct field of inquiry (p. 153). However, should we view this outcome as a failure or a success? Subsequently, marketing scholars have built upon our knowledge of demand generation and fulfillment to study (more broadly) value networks (Lusch et al. 2010). The COVID-19 pandemic has highlighted the interdependency of these two fields of inquiry. The need for a value network perspective is now readily apparent-so that marketers can develop more resilient aggregate marketing systems (p. 152). To me, these changes illustrate how conceptual work is essential for our field to create high impact research. 
Amidst the ebbs and flows of marketing history, we can discern a fundamental shift in marketing scholarship. All marketing articles published between 1995 and 2014 have increasingly focused on value propositions and cocreation (rather than promotion and persuasion) and on customers' mental, experiential, and social wellbeing (Cho et al. 2017). This shift is consistent with the Service Dominant Logic (SDL), which considers markets to consist of actors in a network who cocreate value and increase their well-being by engaging in interdependent and reciprocal exchange of competences for the benefit of another (Lusch and Vargo 2014). My point is that the majority of marketing scholars (some without knowing it) have adopted the theoretical tenets of SDL, with its expansive view of the aggregate marketing system. Thus, conceptual work in our field is evolving in ways that can help us develop research that improves individual, organizational, societal and bioenvironmental well-being.

\section{Pathways for creating impact}

These observations beg the question: Is research in marketing fulfilling its purpose? Pitt emphasizes that academic marketing is the least influential of the business disciplines-prizing rigor over relevance (p.156). Clark summarizes abundant evidence that marketing as an organizational function is increasingly marginalized or "in trouble" (p. 159). Stewart insightfully observes that customer-centricity has simultaneously elevated the importance of marketing phenomena and eroded the marketing function's influence on business decisions (p. 162). Sadly, many managers (wrongly) do not consider marketing a key driver of business success as measured by financial outcomes. Nevertheless, marketing scholarship still has impact through second- and third-order effects that ultimately influence individual, organizational, societal and environmental well-being. However, these effects are difficult to trace. Beyond scholarly publications, there are four pathways to impact that every marketing scholar can follow.

1 Educational Activities and Centers at Business Schools. Our ideas and findings percolate through universities, textbooks and executive education programs. Beyond teaching, business schools house centers which connect marketing scholars (formally or informally) with real world business problems through faculty research, undergraduate and graduate student projects. These activities engage nonprofit, for-profit and governmental organizations around the world.
2 Marketing Institutions and Associations. Academic marketing associations connect marketing scholarship with managerial and public policy decision making. ${ }^{1}$ Plus, through the Marketing Science Institute (MSI), conceptual work in marketing has profoundly influenced brand management, customer insights, marketing communications, metrics and accountability, new products and innovation, services, societal issues and marketing strategy (Bolton 2011).

3 Research Partnerships. Although some scholars contend that managers never use models (p. 160), many marketing models have been so well-accepted that practitioners are unaware of their academic origins! Moreover, marketing scholars around the world (including myself) work with for-profit and nonprofit firms to develop and estimate theory-based marketing models (e.g., Kumar 2017). Based on my experience, managers seek "mental models" (aka marketing theory) that support sense-making and decision-making.

4 Corporate Research and Development (R\&D). Consultancies often transform basic research into practical solutions for the marketplace. Perhaps the halcyon days of corporate R\&D labs (such as Bell Labs) have vanished, but companies such as IBM and Intel, continue to fund and rely on basic research. For example, Jim Spohrer, who is Director, Cognitive Opentech Group at IBM Research Almaden is actively engaged in bridging theory and practice.

These pathways are increasingly augmented by digital and social media that business schools use to communicate key marketing ideas to diverse audiences. Given this understanding of how marketing scholarship is made useful, it is essential that each of us must support and enhance these institutions and activities for our field to have impact.

\section{Research topics and impact}

Let us suppose that (1) many marketing scholars seek to develop knowledge that improves individual, organizational, societal and environmental well-being, and (2) pathways exist (however imperfect) to transform knowledge into high impact outcomes. Nevertheless, over the past decade, marketing thought leaders have warned that our efforts are falling short

\footnotetext{
${ }^{1}$ The American Marketing Association has sponsored the Marketing and Public Policy Conference since 1992 and the Journal of Public Policy and Marketing since 1991. The Association for Consumer Research has supported Transformative Consumer Research that benefits consumer welfare and quality of life. INFORMS has promoted high impact work through the Gary L. Lilien - ISMS - MSI Practice Prize. The Academy of Marketing Science (AMS) sponsors the AMS Review which elevates conceptual work in marketing and the AMS Theory Forum. The Sheth Foundation supports RRBM initiatives by these and other recipient organizations.
} 
(e.g., Lehmann et al. 2011; Reibstein et al. 2009). Hence, KCFSP suggest research topics that will have a high impact. Pitt draws attention to the importance of artifacts and technologies as shapers, biology, information technology, ethics, new ideas, and good writing (p. 156-158). Stewart argues (consistent with SDL) that market exchange concerns intangibles and that-to speak the language of business (finance)-the marketing function requires metrics that link to intangibles (p. 163). I agree wholeheartedly. These observations point to the crux of the KCFSP essays: "Marketing scholars must create more meaningful frameworks and conceptual theorizing about problems that matter" (p. 164, italics mine).

All of us (myself included) should make better choices concerning the topics we study and how we study them to ensure our work has impact. Will a new agenda of research priorities, topics and tools make a difference? We have been down that road many times before-yet we aren't drawing any closer to our destination. Fewer conceptual papers are published in marketing journals than in the past (Yadav 2010). Hence, the marketing discipline needs a new way forward to create high impact theory. The remainder of this commentary describes some concrete steps that every researcher can take.

\section{First steps to creating high impact conceptual research}

Business scholars from around the world are seeking new ways to create high impact research. They have joined together to adopt Responsible Research in Business and Management (RRBM) principles (rrbm.network). The concept of responsible research originated in philosophy of science; it advocates that science should have impact-specifically, it should be useful to society and credible (Tsui 2016). RRBM encourages business research that improves individual, organizational, societal and environmental well-being. The Community for RRBM (2017, p. 3) explicitly notes the role of conceptual work. RRBM's partners include AACSB International (AACSB), the European Foundation for Management Development (EFMD), Principles for Responsible Management Education (PRME), and the Aspen Institute, as well as many universities. Hence, changes in accreditation, faculty hiring, evaluation, promotion and tenure decisions are already underway that will encourage high impact research.

\section{An assessment tool for high impact research}

Marketing scholars can heighten the impact of research projects by using an assessment tool. (See Table 1.) This tool incorporates two RRBM criteria regarding high impact research that are applicable to any business topic. Ideally, this assessment should take place as conceptual work is being developed. It helps a researcher look beyond (narrow) goals of improving business effectiveness and efficiency to consider broader notions of impact. The first criterion identifies the domains in which research can make a useful contribution. Its key question is: In what domain(s) does the research create potential benefits? The top half of Table 1 identifies a broad array of domains. This checklist helps identify high impact topics, such as sustainability, the social effects of artificial intelligence and automation, diversity, inclusion, equality and well-being of employees, implications of advances in technology and biology, and linking the digital and the real world. As KCFSP point out (p. 164), marketing scholars are in a research target rich environment! The second criterion assesses how the research contributes to the well-being of different stakeholder groups (broadly construed) within society. Its key question is: What stakeholders are engaged in the marketing phenomena under investigation and how can they participate and benefit? The lower half of Table 1 identifies many potential stakeholders. This checklist helps identify stakeholders that may have been under-served in prior research: vulnerable populations (e.g., minorities, subsistence communities), technology partners, workers, trade and industry associations, neighborhoods, communities, and the bioenvironment.

\section{Next steps: creating an ecosystem that recognizes and values high impact work}

Individual action is a good place to start, but it is unlikely to achieve our goal of creating high impact theory in marketing. As Yadav (2014, p.1) acutely observes: "Systemic problems necessitate systemic solutions." Hence, we must work together as a marketing community and with other business disciplines. Let me highlight four "next steps" that emerge from KCFSP's essays: the need for improved doctoral student training, counter-acting risk aversion in research topic selection, realigning faculty incentives and rewards within our business schools and leveraging our academic institutions. Most marketing scholars can find ways to support each of these action items in their professional lives. See Table 2. These activities are highly interdependent (Yadav 2014).

\section{Improved doctoral training}

All marketing scholars should have (1) a substantive knowledge of the aggregate marketing system, (2) a grounding theory construction and indigenous marketing theory, and (3) an appreciation for how marketing can contribute to the well-being of individuals, business, society and the bioenvironment. In my experience, doctoral students are plunged into research without this foundation, so they are unable to identify interesting and 
Table 1 Responsible research impact self-assessment tool ${ }^{\mathrm{a}}$

1. Service to Society: Development of knowledge that benefits business and the broader society, locally and globally, for the ultimate purpose of creating a better world. Ask yourself, in what domain(s) does the research provide benefits or make a potential impact?

- Bio-environment

$\circ$ Ecosystems

o Sustainability practices, including zero-waste product and package design, improved demand generation and fulfillment strategies

○ Community and neighborhood

○ Broader geographies (urban/rural neighborhoods, online/offline environments)

o Population health

- Social

○ Human resource management (health and well-being of the workforce, nature of work)

o Transparent and ethical practices online and offline (e.g., privacy)

o Inclusion and equality (gender, race, ethnicity etc.)

o Justice: in labor practices, fairness in serving stakeholders, climate,

o Subsistence markets and under-served communities

o Community and neighborhood well-being

- More expansive business and economic outcomes

o Global prosperity

○ Additional metrics beyond conventional business metrics such as profit, shareholder value, customer satisfaction, and productivity.

o Consideration of network effects and externalities.

$\circ$ Linking digital and real world

○ Implications for policy development

○ Individual, organizational and societal well being

2. Impact on Stakeholders: Research that has the potential to make an impact on diverse stakeholders, especially research that contributes to better business and a better world. Ask yourself, what stakeholders are influenced? Here is a list of potential stakeholders that business research might involve in the study or observe; there may be others.

Consultants \& Research Professionals

Customers

Communities (including neighborhoods)

Educators/ textbook authors

Employees

Funding agencies

Governments, NGOs, trade unions and other associations

Investors

Litigators

Market/business analysts

Nonprofit organizations

Popular (business) news media

Practitioners (e.g., managers)

Public policy (i.e., law) makers

Regulators

Researchers in other disciplines

Shareholders

Boards of directors

Students

Supply or value chain/network partners

${ }^{a}$ These ideas surfaced during a series of discussions among five members of the RRBM Working Board: Bill Glick (Professor of Management, Rice University), Jerry Davis (Professor of Management, University of Michigan), Mark Houston (Professor of Marketing, Texas Christian University), Len Berry (Professor of Marketing, Texas A\&M University) and myself.

important research problems or discern how conceptual work might address them. Yadav (2020) provides excellent direction on "reimagining marketing doctoral programs." He recommends five initiatives: (1) add marketing-focused 
Table 2 High impact research as a social movement

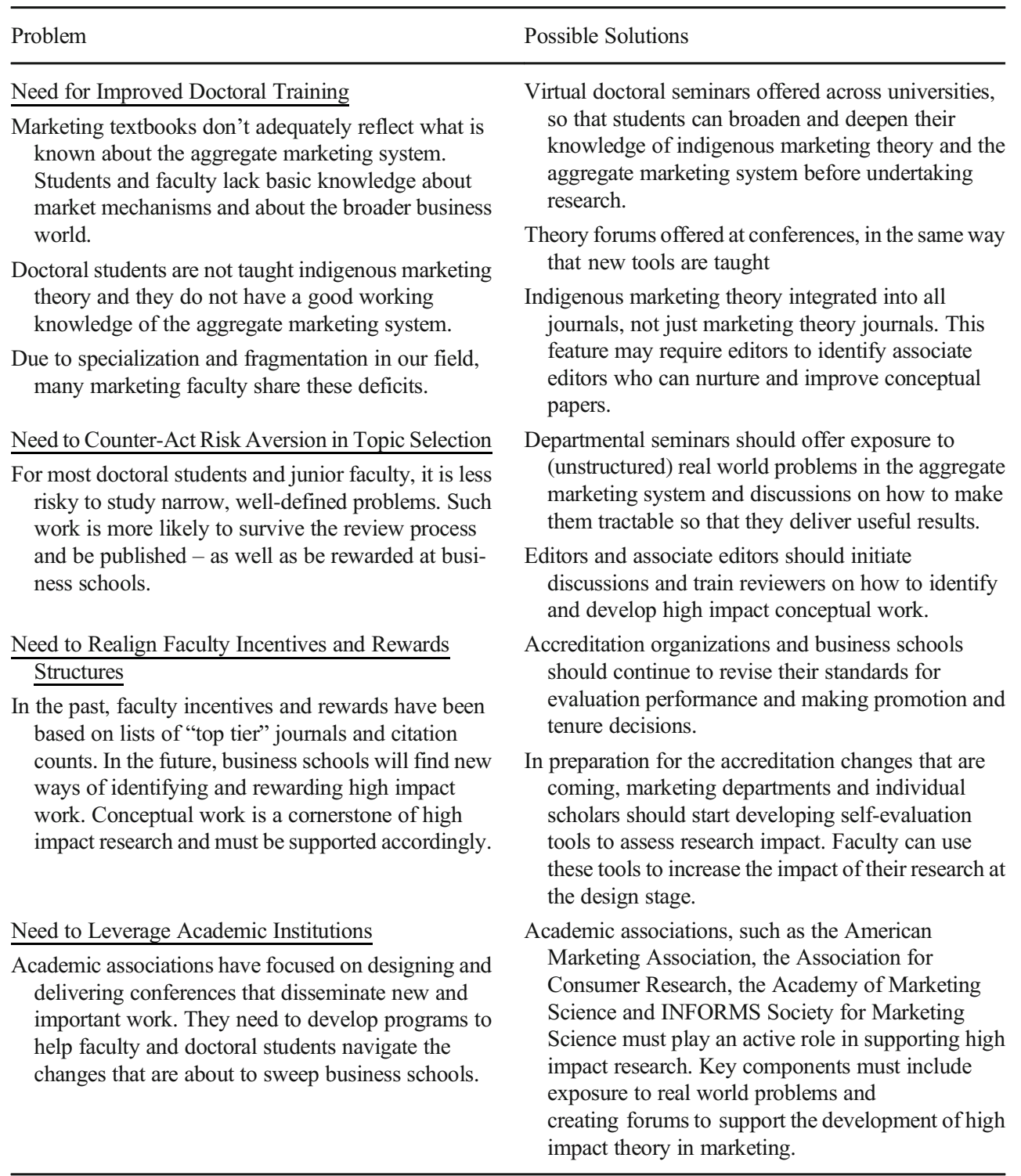

seminars to marketing doctoral programs; (2) dedicate space in the curriculum for marketing theory construction; (3) restructure the sequence of doctoral seminars; (4) make a foundational essay mandatory in dissertations; and (5) change the culture of marketing doctoral programs. These actions do not require vast resources. For example, faculty can collaborate across universities to design and deliver doctoral seminars using virtual learning technologies. These changes will require hard conversations in marketing departments and business schools around the world. However, these conversations are possible if there is a shared understanding of the purpose of business research. With this foundation, academics would be better equipped to follow the prescriptions for conceptual work offered by Hunt (2020), MacInnis (2011), Yadav (2014), Zeithaml et al. (2020) and others.

\section{Counter-acting risk aversion in research topic selection}

Doctoral students want to create high impact research. However, they tell me that it is less risky to study welldefined problems that quickly lead to publications and a first job. Their narrow choices are reinforced as their career progresses. Usually, junior faculty are not exposed to real world problems-nor are they encouraged to tackle them. For example, many marketing departments operate separate behavioral and quantitative research seminars. This situation is not conducive to identifying transdisciplinary, unstructured problems and developing strong conceptual frameworks to make them tractable. These observations suggest that senior faculty must lead the way. (For example, as a Sheth Foundation Board member, I supported the creation of the AMS Review-Sheth 
Foundation Doctoral Student Competition for Conceptual Writing.) Senior faculty have many opportunities because they chair marketing departments, organize research seminars, lead doctoral programs, serve on university committees, and edit journals. Nevertheless, all faculty have an important role to play in identifying and developing high impact conceptual work. RRBM encourages business faculty to endorse RRBM principles and act as change agents by developing their own action plan. See https://www.rrbm.network/endorsers-you/. Each individual researcher must make a conscious effort to develop and support high impact research-especially conceptual work-in all aspects of their professional life.

\section{Realigning faculty incentives and reward structures}

Why should marketing faculty change a system (in any of the ways described in this commentary) when it is currently working in their favor? My answer is simple. Over the past decade, university presidents, business school deans, professional societies, accrediting associations, funding agencies, and the public have realized that business research has failed to offer solutions to real-world challenges (AACSB 2012). The current global pandemic has made these deficiencies apparent to all (McGraw et al. 2020). Hence, a key motivator for all business researchers is that-if we do not change-the current system supporting business research will implode. AACSB has developed new accreditation standards for 879 business schools in $50+$ countries and territories, intended to make business schools a force for good in society. Business schools around the world have begun elevating high impact research and more will follow. Soon, business school deans will ask each faculty member to describe the impact of their work. Will you be able to do so? One way to start a self-assessment is to take a clean sheet of paper and-using the checklist in Table 1 - develop an impact statement for your own work. Then, identify ways to increase the impact of your conceptual work as it develops. Elsewhere, I have described how this improvement might unfold through a simple example (Bolton 2020, p.282). This same approach can be used to improve, recognize and reward the work of all business researchers.

\section{Leverage academic institutions}

Academic associations, such as the American Marketing Association, Association for Consumer Research, INFORMS Society for Marketing Science and the Academy of Marketing Science (AMS) must highlight high impact conceptual work and help researchers navigate the changes sweeping through business schools. The marketing community needs lifelong learning opportunities, such as theory forums. In addition, business schools will play a prominent role. At the 2020 RRBM Summit, Yubo Chen, Senior Associate Dean of Tsinghua University School of Engineering and
Management, described how ten leading business schools in China worked together to create a six-point action plan to transform management research to serve society, including new policies to strengthen and improve post-graduate curriculum, faculty evaluation systems, faculty recruitment and promotional policies, collaborative research relationships between researchers and stakeholders, evaluation of research grants, journal articles, and research projects, and education programs that are best suited to promote management research. These initiatives suggest some important ways that academic associations can elevate high impact conceptual work.

\section{Concluding remarks}

This article started from the premise that marketing scholars have a purpose: to create research that is useful to individuals, organizations, society and the bioenvironment. Strong conceptual work is essential for the marketing discipline to have impact on stakeholders and societal outcomes. There are many opportunities for scholars to generate high impact theoretical contributions-but they require us to step outside our comfort zones. Each of us can choose to prioritize theory-based research that produces useful knowledge that benefits society. Begin today to increase the impact of your research using some of the ideas described in this article. In your institutional (e.g., department chair, program director) and professional (e.g., editorial review board member, conference organizer) roles, change how you assess your own and other scholars' conceptual work using Table 1. I invite you to join RRBM and also to join with others-through the activities described in Table 2-to transform the marketing and business research ecosystem. Always remember that research is "poking and prying with a purpose."

\section{References}

AACSB. (2012). Impact of research: A guide for business schools. Tampa: Association to Advance Collegiate Schools of Business.

Bolton, R. N. (2011). MSI 50: Years ahead. Marketing Management., 20(2), 44-47.

Bolton, R. N. (2017). Autobiographical reflections. Journal of Historical Research in Marketing., 9(3), 244-263.

Bolton, R. N. (2020). Commentary: Future directions of the service discipline. Journal of Services Marketing., 34(3), 279-289.

Brown, S. W., Webster, F. E., Steenkamp, J. B. E., Wilkie, W. L., Sheth, J. N., Sisodia, R. S., Kerin, R. A., MacInnis, D. J., McAlister, L., Raju, J. S., Bauerly, R. J., Johnson, D. T., Singh, M., \& Staelin, R. (2005). Marketing renaissance: Opportunities and imperatives for improving marketing thought, practice, and infrastructure. Journal of Marketing., 69(4), 1-25. 
Cho, Y.-J., Fu, P.-W., \& Wu, C.-C. (2017). Popular research topics in marketing journals 1995-2014. Journal of Interactive Marketing, $40,52-72$.

Community for Responsible Research in Business and Management (2017). A vision of responsible research in business and management: Striving for useful and credible knowledge. Position paper. available at: https://rrbm.network/position-paper/ (accessed 31 January 2020).

Hunt, S. D. (2020). Indigenous theory development in marketing: The foundational premises approach. Academy of Marketing Science Review. 1-10.

Hurston, Z. N. (1942). Dust tracks on a road: An autobiography. London: Hutchinson \& Co..

Key, T. M., Clark, T., Ferrell, O. C., Stewart, D. W., \& Pitt, L. (2020). Marketing's theoretical and conceptual value proposition: opportunities to address marketing's influence. AMS Review. https://doi.org/ 10.1007/s13162-020-00176-7

Kumar, V. (2017). The role of university research centers in promoting research. Journal of the Academy of Marketing Science., 45(1), 453458.

Lehmann, D. R., McAlister, L., \& Staelin, R. (2011). Sophistication in research in marketing. Journal of Marketing., 75(4), 155-165.

Lusch, R. F., \& Vargo, S. L. (2014). The service-dominant logic of marketing: Dialog, debate, and directions. United Kingdom: Taylor and Francis.

Lusch, R. F., Vargo, S. L., \& Tanniru, M. (2010). Service, value networks and learning. Journal of the Academy of Marketing Science., 38(1), 19-31.

MacInnis, D. J. (2011). A framework for conceptual contributions in marketing. Journal of Marketing., 75(4), 136-154.
McGraw, D., Hubler, S. \& Levin, D. (2020). As the virus deepens financial trouble, Colleges turn to layoffs. New York Times. July 16, https://nyti.ms/392uE4W

Reibstein, D. J., Day, G., \& Wind, J. (2009). Guest editorial: Is marketing academia losing its way? Journal of Marketing., 73(4), 1-3.

Tsui, A. S. (2016). Reflections on the so-called value-free ideal: A call for responsible science in the business schools. Cross Cultural and Strategic Management Journal., 23(1), 4-28.

Wilkie, W. L. (2005). Needed: A larger sense of marketing and scholarship. Journal of Marketing., 69(4), 8-10.

Wilkie, W. L., \& Moore, E. S. (1999). Marketing's contributions to society. Journal of Marketing., 63, 198-218.

Wilkie, W. L., \& Moore, E. S. (2003). Scholarly research in marketing: Exploring the 4 eras of thought development. Journal of Public Policy and Marketing., 22(2), 116-146.

Yadav, M. S. (2010). The decline of conceptual articles and implications for knowledge development. Journal of marketing., 74(1), 1-19.

Yadav, M. S. (2014). Enhancing theory development in marketing. AMS Review, 4, 1-4.

Yadav, M. S. (2020). Reimagining marketing doctoral programs. Academy of marketing science review., 10, 56-64.

Zeithaml, V. A., Jaworski, B. J., Kohli, A. J., Tuli, K. R., Ulaga, W., \& Zaltman, G. (2020). A theories in use approach to building marketing theory. Journal of Marketing, 84(1), 32-51.

Publisher's note Springer Nature remains neutral with regard to jurisdictional claims in published maps and institutional affiliations. 